\title{
ANALISIS EKOLOGI MANGROVE SEBAGAI DASAR REHABILITASI DI PESISIR ARAFURA SAMKAI DISTRIK MERAUKE KABUPATEN MERAUKE PROVINSI PAPUA
}

\author{
Siti Masiyah* dan Nova Monika* \\ Staf Pengajar Jurusan MSP UNMUS-Merauke, Email: S.masiyah@yahoo.com
}

\begin{abstract}
ABSTRAK
Pesisir Payum-Lampu satu merupakan salah satu pesisr yang secara geografis berhadapan langsung dengan Laut Arafura. Metode yang digunakan menggunakan metode transek $10 \times 10 \mathrm{~m}$ dengan mengambil sampel pada ekosistem mangrove yang rusak maupun mangrove yang baik. Hasil Penelitian didapatkan kerusakan mangrove di pantai payum disebabkan kareana adanya aktifitas masyarakat sebagai penggali pasir dan memanfaatkan kayu mangrove sebagai bahan bangunan. Hasil pengukuran luasan mangrove yang rusak dengan mengambil koordinat pesisir Kampung payum memiliki panjang mangrove yang rusak 1478,6 $m$ atau 1,5 Km dengan lebar mangrove antara $127-80 \mathrm{~m}$ sehingga didapatkan luasan mangrove yang rusak kurang lebih 2 ha. Adapun koordinat mangrove yang rusak mulai dari $8,51745^{\circ}$ LS - $140,40775^{\circ}$ BT sampai $8,55004^{\circ}$ LS - 140, $41977^{\circ} \mathrm{BT}$. Pesisir Lampu satu memiliki luasan mangrove yang lebih kecil daripada Payum. Penentuan Panjang mangrove yang rusak didapatkan koordinat 8,50049 ${ }^{\circ}$ LS 140,37541 ${ }^{\circ}$ BT Sampai 8,49832 ${ }^{\circ}$ S - 140,36726 ${ }^{\circ}$ BT. Memiliki Panjang pesisir dengan mangrove yang rusak $374 m$ dengan titik koordinat pengukuran pada titik awal: $8,50104^{\circ}$ LS - 140, 36904 ${ }^{\circ}$ BT yang merupakan lebar mangrove yang rusak. Hasil Analisis kualitas air di pesisir payum COD: 22,12- 25,13ppm, DO: 4,63 8,13ppm, 20,46 - 21,34ppm,phosphate: 0,020 - 0,045ppm, nitrat 0,005-0,009ppm sedangkan pada pesisir lampu satu didapatkan COD: 20,72 - 28,17ppm, DO: 3,58 8,79ppm, BOD: 20,11 - 21,39ppm Phosphate :0,019 - 0,060ppm dan nitrat0,009 0,059ppm. Analisis kualitas air dengan perbandingan baku mutu kualitas ir air Kepmen LH No.53Tahun 2004 tentang baku mutu air laut untuk biota. Dan didapatkan sesuai untuk kelangsungan hidup biota. Sedangkan untuk biota yang berasisiasi didapatkan 14 jenis gastropoda dan I jenis bivalvia, di Payum didapatkan Sedangkan di pesisir payum didapatkan 9 jenis gastropoda dan 3 jenis bivalvia.sedangkan untuk jenis ikan yang tertangkap pada ekosistem mangrove yang rusak maupun yang baik didapatkan 10 jenis ikan. Pasang surut yang terdapat pada kedua stasiun sama dimana pasang tertinggi 4,1m dan pasang terendah 3,7 dengan kedalaman pada ekosistem mangrove Payum lebih besar dari pada Lampu Satu.
\end{abstract}

Kata Kunci : Mangrove, kerapatan, keanekaragaman, keseragaman, dominansi biota

\section{PENDAHULUAN}

Kabupaten Merauke yang memiliki batas bagian selatan dengan Laut Arafura, daerah ini terdiri dari perairan laut Arafura sekitar 75.000 $\mathrm{km} 2$, perairan umum (sungai dan rawa) sekitar $71.000 \mathrm{~km} 2$ dan garis pantai $1.050 \mathrm{~km} 2$ yang membentang dari Sungai Torasi diperbatasan
Republik Indonesia dan Papua New Guenia, disebelah timur sampai pada Sungai Syrest (Anonim 2006). Kondisi ekologi yang sangat sesuai untuk kelangsungan ekosisitem mangrove menjadikan kabupaten Merauke Memiliki potensi mangrove yang sangat tinggi. Menurut data menurut data dari wwf 


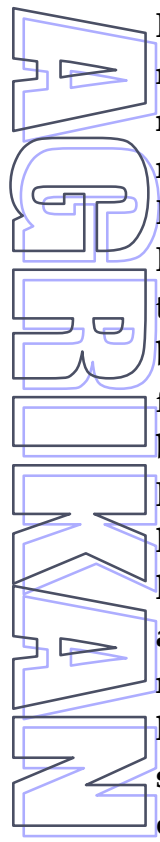

Kabupaten Merauke (2005) dengan menggunakan citra satelit Kabupaten Merauke memiliki luas mangrove 216,196 Ha, sedangkan menurut Bakosurtanal 2009 Kabupaten Merauke memiliki luasan 293.061,159 Ha. Hutan mangrove alami membentuk zonasi tertentu. Jenis mangrove yang berbeda berdasarkan zonasi disebabkan sifat fisiologis mangrove yang berbeda-beda untuk beradaptasi dengan lingkungannya. Keanekaragaman mangrove bukan hanya karena kemampuan untuk beradaptasi dengan lingkungannya tetapi tidak terlepas juga adanya campur tangan manusia untuk memelihara (Nybaken, 1992). Kerusakan lingkungan di wilayah pantai/pesisir Indonesia sampai saat ini belum bisa ditanggulangi dengan optimal. Bahkan yang terjadi saat ini, berbagai kerusakan lingkungan di wilayah pesisir semakin meluas seperti abrasi pantai, kerusakan hutan mangrove dan terumbu karang. Kerusakan lingkungan akan berdampak kepada aktivitas manusia dan lingkungan, seperti rusaknya biota laut, terancamnya pemukiman nelayan, terancamnya mata pencaharian nelayan dan sebagainya.

Usaha rehabilitasi mangrove dipesisir Arafura sudah sering dilakukan, baik oleh pihak Lantamal Wilayah XI Kabupaten Merauke maupun dari Sivitas Universitas Musamus. Usaha penanaman mangrove yang dilakukan selama ini belum memperlihatkan hasil yang kongkrit. Penelitian ekologi mangrove pada daerah yang rusak dan daerah mangrove yang masih baik selama ini belum dilakukan. Mangrove yang memiliki tingkat kerapatan yang tinggi akan memberikan nilai ekosistem dalam mendukung kelestarian sumberdaya pesisir yang berkelanjutan. Sedangkan, mangrove yang rusak akan menghilangkan fungsi mangrove secara ekologi, ekonomi maupun biologi.

Melihat pentingnya nilai ekosistem dalam mendukung kelestarian sumberdaya pesisir, begitu juga ancaman terhadap kelestariannya, maka perlu dilakukan penelitian untuk menentukan Kondisi ekologi mangrove, yang masih baik maupun mangrove yang sudah rusak. Ekologi disini akan melihat perbedaan pada kedua karekter mangrove yang berbeda, dengan melihat beberapa parameter antara lain: Parameter kualitas air dan tanah meliputi (BOD, COD, DO, fosfat, nitrat, susbtrat,suhu dan $\mathrm{pH}$ ). Parameter biologi: meliputi Jenis biota yang berasosiasi pada ekosistem mangrove meliputi: makrozoobentos dan nekton. Sedangkan parameter oceanografi meliputi (Suhu dan pasang surut) di Pesisir Arafura baik pada daerah mangrove yang rusak maupun daerah mangrove yang masih baik. Adapun rumusan masalah dalam jurnal ini meliputi : 1. Bagaimana tingkat parameter kualitas air dan tanah dari parameter kimia, fisika yang meliputi BOD, fosfat, nitrat, Substrat,DO, $\mathrm{pH}$, salinitas dan suhu air. 2.mengidentifikasi dari jenis biota yang berasosiasi pada ekosistem mangrove baik pada makrozoobentos, nekton.3. kondisi oceanografi (pasang surut dan kedalamaan air ) pada ekosistem mangrove yang baik dan ekosistem mangrove yang rusak Analisis ekologi pada ekosistem mangrove sebagai data awal dalam pengelolaan mangrove.

\section{METODOLOGI}

Penelitian akan dilaksanakan dalam waktu lima bulan bulan pada Distrik Merauke Kabupaten Merauke. Survei pendahuluan dilakukan pada awal bulan April 2015 dan penelitian dilakukan sampling pertama tanggal 24 April 2015. Penelitian di laksanakan di pesisir Arafura tepatnya kelurahan Samkai Pantai Payum dan Pantai Lampu satu, Distrik Merauke Kabupaten Merauke Provinsi Papua. Penelitian dilaksanakan selama 3 bulan. parameter kualitas air dari aspek kimia pada kelangsungan hidup makrozoobentos, ikan maupun pada ekosistem mangrove, pada penelitian ini meliputi $\mathrm{Ph}, \mathrm{DO}, \mathrm{COD}$, BOD,Nitrat. Fosphat dan Nitrat. Sedangkan untuk parameter fisika meliputi: suhu air dan salinitas. Parameter biologi meliputi makrozoobentos dan nekton. Pengambilan sampel tanah (substrat) pada masing-masing transek dilakukan tiga kali ulang yaitu pada awal, tengah dan akhir penelitian. Pengamatan terhadap parameter kualitas tanah dilakukan secara vertikal dan hanya sampai batas lapisan top soil (20-30), mengambil sampel tanah sebanyak $\pm 1 \mathrm{~kg}$ yang dimasukan dalam kantong plastik selanjutnya dianalisis dilaboratorium Ilmu Tanah Fakultas Pertanian Universitas 


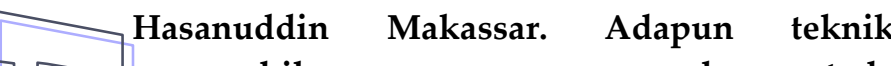
pengambilan mangrove menggunakan metode transek line, dengan menempatkan plot pada masing-masing zonasi dengan ukuran $10 \times 10 \mathrm{~m}$ pada ekosistem mangrove, berdasarkan tukuran $10 \times 10 \mathrm{~m}$, merupakan plot untuk pengambilan sampling mangrove, subplot dengan ukuran $5 \times 5 \mathrm{~m}$ merupakan tempat sampling anakan mangrove dan subplot dengan ukuran 1 x1 m, merupakan tempat sampling makrozoobentos. pengambilan ikan dengan menggunakan metode jelalah dengan tehnik random atau acak dimana pengambilan sampel dilakukan secara bebas pada daerah penelitian. Dilakukan pada ekosistem mangrove yang masih baik maupun yang sudah rusak. Alat tangkap yang digunakan untuk menangkap ikan pada daerah mangrove yang masih baik menggukan jaring dan untuk daerah mangrove yang rusak menggunakan jala. Pengambilan kualitas air (COD,BOD,Nitrat,fosfat) dilakukan pada waktu air pasang, baik pada daerah mangrove yang masih baik maupun mangrove yang sudah rusak dengan melakukan pengambilan air sebanyak $600 \mathrm{ml}$, kemudian disimpan pada suhu 40C atau dimasukkan ke coolbox, lalu sampel dianalisis di Universitas Hasanuddin Makassar dan sebgaian dilakukan di laboratorium Universitas Ghajah Mada Yogyakarta. oceanografi untuk pasang surut dilakukan 3 hari berturut - turut,dengan menggunakan kayu berskala dipasang pada daerah yang mangrovenya sudah rusak dan yang masih baik.

\section{HASIL DAN PEMBAHASAN}

3.1. Kondisi Pesisir Payum - Lampu Satu Distrik Merauke Kab. Merauke

Pesisir Payum - Lampu satu merupakan salah satu pesisr yang secara geografis berhadapan langsung dengan Laut Arafura. Secara ekologis pesisir payum - Lampu satu sangat strategis dan memiliki potensi perikanan yang sangat tinggi. Selain itu kondisi perairan pesisir ini sangat dipengaruhi input air tawar dari kali Maro. Wilayah ini seacara administrasi merupakan lingkup wilayah Distrik Merauke dengan garis pantai sekitar $3,2 \mathrm{~km}$. masyarakat pesisir yang memiliki pekerjaan utama sebagai penggali pasir dan nelayan yang melakukan penangkapan disekitar pesisir Payum - Lampu Satu selain itu juga melakukan penangkapan diperairan Arafura atau daerah perbatasan dengan Papua new Guine.

Pesisir Payum - Lampu Satu dengan karakter substrat pasir dan debu menjadikan mangrove dapat tumbuh dengan baik. Terdapat berbagai jenis mangrove di Pesisir Arafura Distrik Merauke Menurut Masiyah, S. dan Sunarni (2014) didapatkan 14 Jenis Mangrove antara lain: Rhizophoramukronata, Sonneratia alba, Rhizophorastylosa, Brugueira hainessii, Brugueira gymnorrhiza, Ceriopde candra, Avicennia officinalis, Avicennia marina, Bruguiera cylindrical, Cerioptegal, Avicennia alba, Aegialitis annulata, dan Osbornia oktodonta.

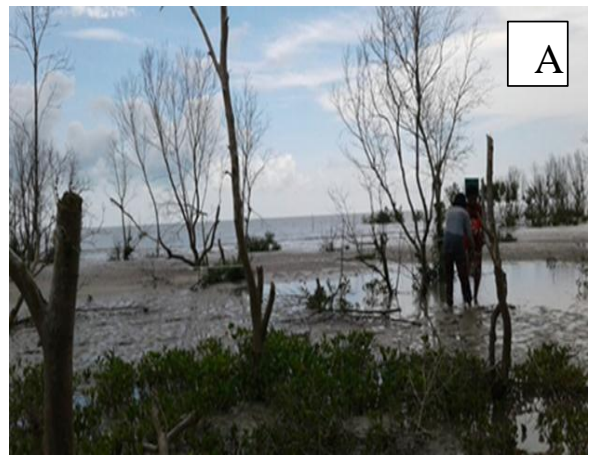

Gambar 1. Kondisi mangrove pesisir payum

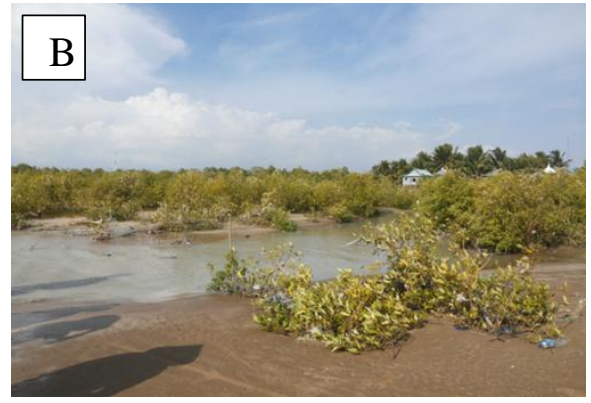

Gambar 2. Kondisi mangrove Pesisir Lampu Satu

Hasil Penelitian didapatkan kerusakan mangrove di pantai payum disebabkan karena adanya aktifitas masyarakat sebagai penggali pasir dan memanfaatkan kayu mangrove sebagai bahan bangunan. Selain itu, hasil pengukuran luasan mangrove yang rusak dengan mengambil koordinat pesisir Kampung payum memiliki panjang mangrove yang rusak $1478,6 \mathrm{~m}$ atau $1,5 \mathrm{Km}$ dengan lebar mangrove 
antara 127 - $80 \mathrm{~m}$ sehingga didapatkan luasan

3 mangrove yang rusak kurang lebih 2ha. Adapun koordinat mangrove yang rusak mulai dari $8,51745^{\circ}$ LS - $140,40775^{\circ}$ BT sampai $8,55004^{0}$ LS - 140, $41977^{0}$ BT. Memiliki Kedalaman air paling tinggi untuk ekosistem mangrove yang rusak ketika pasang mencapai $86 \mathrm{~cm}$. Sedangkan di Pesisir Lampu satu memiliki luasan mangrove yang lebih kecil daripada Payum.

\subsection{Analisis Kualitas Air Pada Ekosistem Mangrove}

Hasil analisis kualitas air pada ekosistem mangrove pada pesisir Payum Maupun lampu satu dapat dilihat pada Tabel 1. Tabel Standar baku mutu air laut untuk biota kepmen no 51 tahun 2004 (Tabel 2).

Tabel 1. hasil Analsis kimia air pada ekosistem mangrove

\begin{tabular}{|c|c|c|c|c|c|c|}
\hline \multirow[t]{2}{*}{ No } & \multirow[t]{2}{*}{ Kode Sampel } & $\begin{array}{l}\text { Chemical } \\
\text { Oxygen } \\
\text { Demand } \\
(C O D)\end{array}$ & $\begin{array}{c}\text { Dissolves } \\
\text { Oxygen } \\
\text { (DO) }\end{array}$ & $\begin{array}{c}\text { Biochemical } \\
\text { Oxygen } \\
\text { Demand } \\
\text { (BOD) }\end{array}$ & $\begin{array}{c}\text { Total } \\
\text { Phosphorus } \\
\text { (TPO4) }\end{array}$ & $\begin{array}{l}\text { Nitrat } \\
\text { (NO3) }\end{array}$ \\
\hline & & \multicolumn{5}{|c|}{$\operatorname{Ppm}(m g / L)$} \\
\hline 1 & Payum 1 & 25.13 & 4.63 & 20.46 & 0.045 & 0.005 \\
\hline 2 & Payum 2 & 23.15 & 6.56 & 21.43 & 0.020 & 0.008 \\
\hline 3 & Payum 3 & 22.12 & 8.13 & 20.79 & 0.040 & 0.009 \\
\hline 1 & Lansat 1 & 28.17 & 3.58 & 21.39 & 0.019 & 0.009 \\
\hline 2 & Lansat 2 & 25.56 & 6.53 & 20.11 & 0.020 & 0.012 \\
\hline 3 & Lansat 3 & 20.72 & 8.79 & 20.23 & 0.060 & 0.059 \\
\hline
\end{tabular}

Tabel 2. Tabel Standar baku mutu air laut

\begin{tabular}{clc}
\hline N0 & \multicolumn{1}{c}{ Parameter } & Baku (Air laut untuk Biota) \\
\hline 1 & pH & $7-8,5$ \\
2 & suhu & $28-32$ \\
3 & salinitas & 34 \\
4 & DO & $>5$ \\
5 & BOD & 20 \\
6 & Fosphat (PO4-p) & 0,05 \\
7 & Nitrat & 0,008 \\
\hline \hline
\end{tabular}

Tabel 3. Parameter suhu, salinitas dan tekstur tanah pesisir Payum - Lampu Satu

\begin{tabular}{|c|c|c|c|c|c|}
\hline \multirow[b]{2}{*}{ No } & \multirow[b]{2}{*}{ Koordinat } & \multicolumn{4}{|c|}{ Parameter (Payum) } \\
\hline & & Suhu $\left({ }^{\circ} \mathrm{C}\right)$ & $\mathrm{pH}$ & $\begin{array}{l}\text { Salinitas } \\
\text { (Permil) }\end{array}$ & Tektur Tanah \\
\hline 1 & $8,55446^{\circ} \mathrm{LS}-140,42556^{\circ} \mathrm{BT}$ & 27 & 7.8 & 18 & Pasir berlempung \\
\hline 2 & $8,52634^{\circ} \mathrm{LS}-140,41644^{\circ} \mathrm{BT}$ & 28 & 8.4 & 22 & Pasir berlempung \\
\hline 3 & $8,53447^{\circ} \mathrm{LS}-140,41949^{\circ} \mathrm{BT}$ & 32 & 8.4 & 32 & Pasir \\
\hline \multirow[b]{2}{*}{ No } & \multirow[b]{2}{*}{ Koordinat } & \multicolumn{4}{|c|}{ Parameter (Lampu Satu) } \\
\hline & & Suhu $\left({ }^{\circ} \mathrm{C}\right)$ & pH & $\begin{array}{c}\text { Salinitas } \\
\text { (Permil) }\end{array}$ & Tektur Tanah \\
\hline 1 & $8,49915^{\circ} \mathrm{LS}-140,37448^{\circ} \mathrm{BT}$ & 28 & 7.8 & 18 & Pasir berlempung \\
\hline 2 & $8,49555^{\circ} \mathrm{LS}-140,36547^{\circ} \mathrm{BT}$ & 30 & 8.6 & 24 & Pasir berlempung \\
\hline 3 & $8,4993^{\circ} \mathrm{LS}-140,374169^{\circ} \mathrm{BT}$ & 33 & 8.3 & 33 & Pasir \\
\hline
\end{tabular}

Hasil analisis kualitas air dengan mengacu pada standar baku mutu air laut untuk biota mengacu pada kepmen no 51 tahun 2004. Pada pesisir payum dan lampu satu dengan melihat analisis suhu, salinitas,Nirat,
Phosphat, COD, BOD sangat cocok atau sesuai untuk kelangsungan mangrove dan biota yang berasosiasi. Sedangkan untuk hasil analisis substrat pada ekosistem mangrove yang rusak terdapat jenis tanah pasir yang lebih besar 


(190\%) dan Debu (10\%) sedangkan untuk mangrove yang baik didapatkan $70 \%$ pasir dan $30 \%$ dan termasuk dalam kategori tanah pasir berlempung sedangkan untuk mangrove yang terletak disekitar Anakan sungai $67 \%$ pasir dan $33 \%$ debu yang masuk dikategorikan tipe tanah pasir berlempung. Salinitas yang rendah terdapat pada ekosistem mangrove yang terletak disekitar sungai sedangkan pada ekosistem yang rusak terdapat salinitas yang sanagat tinggi. Biota yang berasosiasi pada ekosistem mangrove.

3.3. Makrobentos dan Spesies Ikan

Hasil identifikasi makrobentos didapat didapatkan 14 jenis, 7 genus antara lain: Genus Nassarium, genus cantharus, littorina, cerithidae, Cassidulan, Terebaralia, dan Vessilum. makrobentos di pesisir Lampu satu (Tabel 4). Sedangkan Hasil identifikasi ikan

Tabel 4. Identifikasi biota Gastropoda dan Bivalvia Pesisir Payum dan Lampu satu

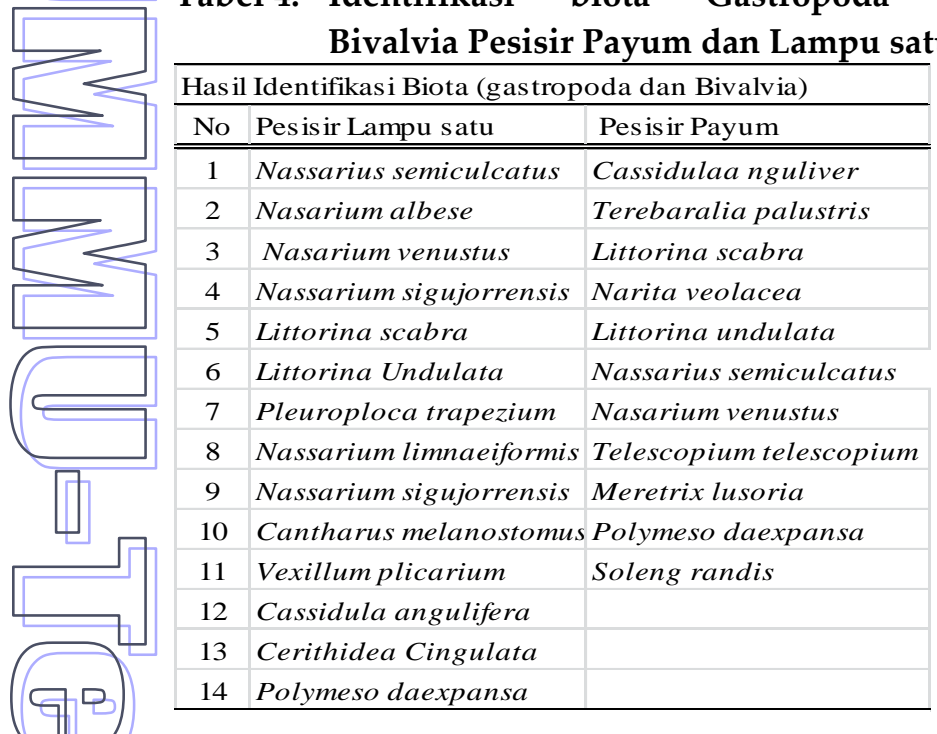

\subsection{Parameter Oceanografi}

Pengkajian Oceanografi pada pesisir Arafura adalah pasang surut dan kedalaman perairan pada ekosistem mangrove yang baik maupun yang rusak. Asapun tinggi gelombang yang dilakukan selama penelitian dapat dilihat pada Tabel 6. dari Pesisir Lampu satu dan Pesisir Payum memiliki jumlah yang sama yaitu 11 jenis ikan dan 2 biota yang masuk dalam golongan crustace (Tabel 5.). Mengenai lebih detil jenis ikan yang tertangkap pada pesisir Payum dan Lampu satu hasil penangkapan ikan pada kedua stasiun didapatkan jenis ikan yang sama atau tidak berbeda hal ini bias terjadi karena kedua pantai tersebut merupakan satu gugusan pesisir yang berhadapan langsung dengan laut Arafura. Diamana masyarakat nelayan yang terdapat melakukan penebaran jaring selain mengarah pada lampu satu juga terdapat pada pesisir payum. Begitu juga ikan yang berasosiasi pada ekosistem mangrove ketika terjadi pasang ikan akan beruaya ke mangrove baik pada mangrove yang rusak, baik maupun pada anakan sungai yang terdapat pada ekosistem mangrove.

Tabel 5. Identifikasi Ikan dan Crustacea

\begin{tabular}{l}
\hline Jenis ikan dari Pesisir Payum -Lampu satu \\
\hline \hline Ikan sumpit (strongylura-strongyluro ) \\
\hline Gulamah ( Johnins sp ) \\
Ikan kakap (Lates calcaliver ) \\
Ikan tembang ( hilsa kelee) \\
Ikan duri (Arius sp ) \\
Ikan Lidah (Cynoglossus heterolepis) \\
Ikan Kaca ( Kurtus gulliveri) \\
Bandeng (Chanos - chanos) \\
Ikan sembilang / Plototus canus \\
Ikan Bambit / Drepane sp \\
Ikan gelodok (Mudskipper) \\
Scylla serrata/ kepiting bakau \\
Penaeus Vannamei/ udang putih \\
\hline
\end{tabular}

Tabel 6. Tinggi gelombang dan kedalaman daerah sampling

\begin{tabular}{c|c|c|c|c}
\hline \multirow{2}{*}{ sampling } & \multicolumn{2}{|c}{ pasang tinggi } & \multicolumn{2}{c}{ kedalaman } \\
\cline { 2 - 5 } & Payum & Lampu Satu & Payum & Lampu Satu \\
\hline \hline 1 & $4,1 \mathrm{~m}$ & $4,1 \mathrm{~m}$ & $80 \mathrm{~cm}$ & $40 \mathrm{~cm}$ \\
\hline 2 & $3,8 \mathrm{~m}$ & $3,8 \mathrm{~m}$ & $64 \mathrm{~cm}$ & $23 \mathrm{~cm}$ \\
\hline 3 & $3,7 \mathrm{~m}$ & $3,7 \mathrm{~m}$ & $60 \mathrm{~cm}$ & $15 \mathrm{~cm}$ \\
\hline \hline
\end{tabular}

Pasang tinggi dan kedalaman perairan dalam ekosistem mangrove tidak ada ketentuan besarnya dalam angka. Tinggi gelombang masing - masing daerah memiliki karakteristik yang berbeda. Tinggi gelombang 
disini sangat terkait dengan pasang surut, dimana pada saat pasang tertinggi didapatkan jumlah air yang melimpah pada ekosistem mangrove dan pada saat surut terendah benar tidak didapatkan air. Pada pesisir lampu satu memiliki pasang tinggi yang sama dengan pesisir payum hal ini dikarenakan pada kedua pesisir masih terdapat pada satu gugus pesisir Arafura. Sedangkan kedalaman yang berbeda pada kedua Pesisir, pada pesisir payum memiliki kedalaman yang lebih besar dari pada kedalaman Lampu satu hal ini di karenakan pada pesisir Lampu Satu kerusakan mangrove sudah sangat tinggi yang sudah ada pemasangan break weter sehingga air ketika terjadi pasang tinggi gelombang yang masuk sudah mengalami perpecahan sehingga air yang masuk memiliki waktu yang lebih singkat atau berkurang dalam volumenya.

\section{KESIMPULAN DAN SARAN}

\subsection{Kesimpulan}

1. panjang mangrove yang rusak $1478,6 \mathrm{~m}$ atau $1,5 \mathrm{Km}$ dengan lebar mangrove antara 127 $50 \mathrm{~m}$ sehingga didapatkan luasan mangrove yang rusak kurang lebih 2ha. Penentuan Panjang mangrove yang rusak didapatkan koordinat $8,50049^{\circ} \mathrm{LS}-140,37541^{\circ} \mathrm{BT}$ Sampai

$8,49832^{\circ} \mathrm{LS}-140,36726^{\circ} \mathrm{BT}$.

2. Kualitas air yang ada di pesisir payum dan lampu satu sesuai untuk kelangsungan hidup mangrove dan biota yang berasosiasi dan sesuai dengan Kepmen No. 51 tahun 2004 tentang baku mutu air laut untuk biota

3. Biota yang berasosiasi didapatkan 11 jenis ikan dan 2 jenis crustacea. Sedangkan untuk 14 jenis, 7 genus antara lain: Genus Nassarium, genus cantharus, littorina, cerithidae, Cassidulan, Terebaralia, dan Vessilum.

4. Pasang surut yang terdapat pada kedua stasiun sama dimana pasang tertinggi $4,1 \mathrm{~m}$ dan pasang terendah 3,7 dengan kedalaman pada ekosistem mangrove Payum lebih besar dari pada Lampu Satu.

\subsection{Saran}

1. Perlu dilakukanya penelitian aspek sosial masyarakat terhadap potensii ekosistem mangrove.

2. Sosialisasi tentang pentingnya ekosistem mangrove kepada masyarakat terutama masyarakat pesisir.

\section{DAFTAR PUSTAKA}

Abdulhaji, R., 2001. Problem of issues affecting biodiversity in Indonesia. Situation analysis. Paper. Presented in Workshop on Tanning Net Assessment for Biodiversity Conservation in Indonesia 1-2 Februari 2001, Bogor, Indonesia.

Anonim, 2006. Buku 1 Potret Sumberdaya Kawasan Laut Arafura dan Laut Timor Menuju Pembangunan Berkelanjutan. Forum Pakar Laut Arafura dan Laut Timor.

Antonio de Jesus, 2012. Kondisi ekosistim mangrove di sub district Liquisa Timor- LesteMangrove ecosystems condition in Liquisa sub district Timor-Leste. Jurnal ISSN 2089-7790.

Arisandi, dkk. (2014). Eksternalitas Penambangan Pasir Pantai Secara Tradisional Terhadap Ekosistem Mangrove dan Sosial Ekonomi Masyarakat Pesisir di Kabupaten Merauke. Jurnal Universitas Terbuka Pasca Sarjana, Jakarta

Bengen, D. G. 2004. Pedoman teknis: Pengenalan dan pengelolaan ekosistem mangrove. PKSPLIPB. Bogor.

Dahuri dkk (2006). Pengelolahan Wilayah Pesisir Terpadu Penerbit Pradnya

Effendi, H. 2003. Telaah Kualitas Air Bagi Pengelolaan Sumber Daya dan LingkunganPerairan. Yogyakarta: Percetakan Kanisius.Paramita. Surabaya

Fachrul, M.F. 2008. Metode Sampling Bioekologi. Penerbit: Bumi Aksara. Jakarta

Fadli, dkk. (2013). Studi Zonasi Mangrove di Muara Sungai Kawal Kelurahan Kawal Kecamatan Gunung Kijang Kabupaten Bintan. Jurnal Ilmu Kelautan dan perikanan Universitas Maritim Raja Ali Haji Jakarta

Hartini, S., G. B. Saputro, M. Yulianto, Suprajaka. 2010. Assessing the Used of Remotely Sensed Data for Mapping Mangroves Indonesia. Selected Topics in Power Systems and Remote 
Sensing. In 6th Wseas International Conference on Remote Sensing (Remote'10), Iwate Prefectural University, Japan. October 4-6, 2010; pp. 210-215

Harahap, 2010. Penilaian ekonomi Ekosistem hutan Mangrove dan Aplikasinya dalam Perencanaan Wilayah Pesisir. Graha Ilmu

Insafitri. 2010. Keseragaman, dan Dominansi Bivalvia di Area Buangan Lumpur Lapindo Muara Sungai Porong. Jurnal Kelautan. Universitas Trunojoyo. Jurnal kelautan. ISSN1907-9931

Irwanto, 2006. Keanekaragaman Fauna Pada Habitat Mangrove

Kusmana, C. 2005. Manajemen hutan mangrove Indonesia. Lab Ekologi Hutan. Jurusan Manajemen Hutan, Fakultas Kehutanan, IPB. Bogor.

Latupapua. M.J.J (2010). Keanekaragaman JenisNekton di Mangrove Kawasan Segoro Anak Taman Nasional Alas Purwa Jurnal Politekninik Perdamaian Halmahera- Tabelo. ISSN : 19077556

Masiyah, S dan Sunarni (2014). Komposisi Jenis dan kerapatan mangrove Pesisir Arafura Distrik Merauke Kabupate Merauke Provinsi Papua. Jurnal Agicola Fakultas Pertania Universitas Musamus

Noortiningsih, Ikna Suyatna Jalip, Sri Handayani. 2008. Keanekaragaman Makrozoobenthos, Meiofauna Dan Foraminifera Di Pantai Pasir Putih Barat Dan Muara Sungai Cikamal Pangandaran Jawa Barat. Vis Vitalis 1 (1). Fakultas Biologi. Universitas Nasional. Jakarta

Nybakken, J.W. 1992. Biologi Laut Suatu Pendekatan Ekologis. Alih Bahasa oleh PT. Gramedia Pustaka Utama Jakarta Indonesia

Onrizal. 2005. Adaptasi Tumbuhan Mangrove pada Lingkungan Salin dan Jenuh Air. Universitas Sumatra Utara. http://e-USU Repository.

Pratikto, W. (2002). Perencanaan perlindungan pantai alami untuk mengurangi resiko terhadap bahaya tsunami. Makalah disampaikan dalam lokakarya nasional Pengelolaan Ekosistem Mangrove di Jakarta, 6-7 Agustus 2002. Kementerian Perikanan Republik Indonesia.

Vatria, B. (2010). Berbagai kegiatan manusia yang dapat menyebabkan terjadinya degradasi ekosistem pantai serta dampak yang ditimbulkannya. Jurnal Belian V( 9), 47-54.

Widyastuti, M. dan S. L. Wahyu, 1998. Identifikasi dan Pengukuran Parameter Fisik di Lapangan. Kerjasama Fakultas Geografi-UGM dengan Bakosurtanal BANGDA dalam rangka Proyek MREP Sulawesi Selatan.

Wiratmini.N.I, dkk.(2006). Makrozoobenthos Partai Pererenan (Kabupaten Bandung): Jenis, Status dan manfaaatnya Bagi Masyarakat.Jurnal Biologi, FMIPA, Universitas Undayana Bali. Jurnal Bumi Lestari, Vol.8 No. 2, Agustus 2008. Hal 176-179

WWF Kabupaten Merauke (2005) Luasan Mangrove Kabupaten Merauke. Dengan menggunakan data Citra.

Yulianda dkk, 2009. Pengelolahan Ekosistem Mangrove di Indonesia. Penerbit Graha Ilmu

Zaky, Abdul R. 2012. Kajian Kondisi Lahan Mangrove di Desa Bedono, Kecamatan Sayung, Kabupaten Demak dan Kelurahan Mangunharjo, Kecamatan Tugu, Kota Semarang. Jurnal of Marine Research.1 (2) : 88-97. http://ejournal-s1.undip.ac.id/index.php/jmr. 